\title{
EFFECT OF ABANDONMENT OF COOLING AND LUBRICATION ON SURFACE ROUGHNESS AND CYLINDRICITY IN TURNING OF STEEL
}

\author{
Antal Nagy \\ PhD student, Institute of Manufacturing Science, University of Miskolc \\ 3515 Miskolc, Miskolc-Egyetemváros, e-mail: antal.nagy@uni-miskolc.hu \\ Gyula Varga \\ Associate professor, Institute of Manufacturing Science, University of Miskolc \\ 3515 Miskolc, Miskolc-Egyetemváros, e-mail: gyula.varga@uni-miskolc.hu
}

\begin{abstract}
One of the defining global issues today is to reduce the load on the environment. Thus, in this paper, the effect, and consequences of the abandonment of cooling and lubrication were investigated when turning of non-alloyed steel. The $2 D$ and $3 D$ surface roughness parameters, cylindricity deviations and circularity errors were examined at different feeds and cutting speeds. The experiments were performed, using the full factorial experimental design method. It was found that with dry machining, the average roughness is slightly higher with increasing productivity, however, at lower feed and cutting speeds, the surface has better wear resistance and lubricant retention, and cylindricity deviation can be minimized.
\end{abstract}

Keywords: turning, surface roughness, cylindricity deviation, environmentally friendly machining

\section{Introduction}

The use of coolants-lubricants (CL) in machining improves the quality and accuracy of manufactured parts, increases productivity, and helps remove chips from the cutting region. At the same time, their use pollutes the environment (Dudás et al., 2010; Kundrák et al., 2018), and in addition to its high cost, they can also cause skin and breathing problems for machine operators (Saliminia and Abootorabi, 2019). Therefore, the environmental protection (which is becoming increasingly important worldwide) aims in machining to the minimization or abandonment of CLs. It is further exacerbated by the fact that their use is particularly high worldwide. There are several possibilities associated with this (Kundrák et al., 2018): the use of naturally occurring and degradable oils (Bonfá et al., 2019; Derani and Ratnam, 2021; Gariani et al., 2021), the reduction of the amount used (e.g., Minimum Quantity Lubrication, MQL) (Bonfá et al., 2019; Gupta et al., 2020; Niknam and Jalali, 2020; Zaman and Dhar, 2019), the change of composition, or the omission of cooling-lubrication (Gupta et al., 2019; Leppert, 2011). The latter was pointed out by Kundrák et al. (Kundrák et al., 2018) in the study of the machining of case-hardened steel gear hole. Three strategies were compared in terms of productivity and the amount of CL fluid used; hard turning, conventional traverse bore grinding and combined machining (turning and grinding). It was found that in contrast to grinding, the combined process requires less cutting fluid in a shorter machining time, but more importantly, the CBN insert used in hard turning allows dry machining with high productivity, making the latter the most environmentally friendly choice.

In the field of cooling-lubrication and environmental protection, MQL and MQCL (Minimum Quantity Cooling and Lubrication) have been central issues in the last decade, the application of which shows promising results (Gupta et al., 2019; Leppert, 2011; Joshi et al., 2018; Varga and Kundrák, 2013). In addition 
to reduce the cost of excipients and the environmental impact, the cutting temperature is lower (Gupta et al., 2020), which makes the chip morphology smoother and more discontinuous, and has a direct effect on reducing surface roughness and tool wear. Also, the range of cutting speeds characteristic of built-up edge formation is shifted, and the tool life is expected to increase (Gupta et al., 2019) as opposed to both dry and conventional cooling and lubrication. When turning an aluminum alloy (Niknam and Jalali, 2020), it was found that the chip thickness was not affected by the CL fluid type and flow rate. The best surface quality improving effect was achieved with a higher viscosity, biodegradable cutting fluid. During hard turning of a hardened steel, the resulted $\mathrm{R}_{\mathrm{a}}, \mathrm{R}_{\mathrm{q}}$ and cutting temperature decreased by 23-24\% compared to dry cutting (Gupta et al., 2020). Zaman et al. studied [9] the MQL method with embedded double jet nozzle in which greater reductions in cutting temperature, roughness (-15\%), cutting force, and tool wear ( $+37 \%$ tool life) were measured compared to MQCL method with single nozzle. In the same procedure, Bonfá et al. (Bonfá et al., 2019) found that using the MQL technique, cooling and lubrication significantly reduced tool flank wear, but had a small reducing effect on surface roughness compared to dry machining. Leppert (Leppert, 2011) observed lower values of average roughness $R_{a}$ in most cases of the settings with MQL and found the largest decrease at lower feed rate and lower cutting speed. Gupta et al. (Gupta et al., 2019) observed that in addition to the different nano-cutting fluids used, the cutting force, tool wear and surface roughness also showed similar characteristics, the examined cutting parameters significantly influenced them. Joshi et al. (Joshi et al., 2018) experienced less flank wear and better surface quality under MQL conditions during turning of Incoloy-800 steel. Varga et al. (Varga and Kundrák, 2013) evaluated the effect of MQL in dry helical turning using 3D roughness parameters. They found that the roughness $S_{a}$ of dry milled surfaces was larger in all cases, but the effect of changing the feed and cutting speed became smaller.

The MQL technique is also applied and studied using nano-cutting fluids. In doing so, certain liquid properties (thermal conductivity, viscosity, surface tension, contact angle) are changed by dispersing nanoparticles in deionized water (Das et al., 2021). An investigation (Das et al., 2021) reported in hard turning of steel that the effect of different oxide nanoparticles was significant in cutting force (maximum $44 \%$ deviation), workpiece residual stress and was minor in flank wear and average roughness. In turning of a nickel-based superalloy, their change showed a similar nature of the output characteristics (force, roughness), though the effect of the changes of the examined cutting parameters was more significant (Gupta et al., 2019).

Another method of reducing the environmental impact is the use of biodegradable cutting fluids of plant origin. The efficiency of their applicability is evaluated according to several aspects (Derani and Ratnam, 2021), these are typically flank wear, cutting force, roughness, temperature, vibration, chip formation, etc. When turning titanium alloy (Gariani et al., 2021), it was found that while the feed and tool type had a strong effect on roughness and flank wear, the cutting fluid concentration had a slight reducing impact, the best results (for roughness and flank wear) were obtained at $5 \%$ oil concentration.

Cryogenic machining is one of the emerging manufacturing techniques in the machining industry regarding the use and disposal of chemically contaminated conventional coolants due to new strict environmental regulations (Sivaiah and Chakradhar, 2020). Temperature control during machining makes it possible to comply with the shape, size and design specified for the components (Araújo et al., 2019). In doing so, liquid nitrogen $\left(\mathrm{LN}_{2}\right)$ is used for cooling (Bogajo et al., 2020), about which we briefly summarize some research results. Saliminia et al. (Saliminia and Abootorabi, 2019) investigated the effect of this on surface roughness and chip ratio in stainless steel turning. Compared to dry machining, the chip ratio increased by an average of $32 \%$ and chip breaking improved during cryogenic machining. Also, the cutting force and tool vibration were reduced, thus reducing the surface roughness (by 13\% on average). Kim et al. (Kim et al., 2018) observed that in hard turning, the cryogenic coolant increased the cutting force as well as the segment angle due to the increase in the thermal gradient during chip formation. Flank wear 
was observed under both wet and dry conditions, with liquid nitrogen the amount of flank wear was reduced by $12-27 \%$. Araújo et al. (Araújo et al., 2019) presented a steam compression cooling system for cooling cutting fluid. By keeping the temperature of the fluid low, it contributes to increase the life of the fluid while preserving its properties for a longer period. Also, it reduces the growth of fungi and bacteria, thereby lowering the time frequency of fluid replacement, which is beneficial for the environment. The values of the average roughness were very close to each other, in the cooled and non-cooled cases, the tendency of the lower average roughness was observed with CL fluid having low temperature. In addition, an advantage of the system is its acquisition cost; it is $1.5 \%$ of the cost of a high-pressure jet engine system, $3 \%$ of the cost of a cryogenic cooling system, and 30-60\% of a compressed air-cooled vortex.

There are research works in other fields related to environmentally friendly machining as well. One example for that is a study (Gajrani et al., 2018) in which a special cutting equipment was presented which contained molybdenum-disulfide $\left(\mathrm{MoS}_{2}\right)$ solid lubricant in a mechanically developed texture to form a selflubricating tool, thus the traditional CL fluid was omitted, much less lubricant was used, and lubrication was also much more effective in terms of tool wear, cutting force and surface roughness.

Surface quality is an important property of the surfaces of a component in terms of operation, fit, surface treatment, appearance, etc. so that a machining process can be well characterized by it, because of the machining. This includes surface roughness and shape errors and among them, cylindricity deviations. Therefore, not only the effect of cutting data (Kundrak and Felho, 2016; Felho and Kundrak, 2012; Masoudi et al., 2019) but the effect of cooling-lubrication (Masoudi et al., 2019) can be evaluated on such bases as well.

In this paper, the effect of cooling and lubrication is investigated on 2D profile and 3D roughness parameters and cylindrical characteristics on turned surfaces. Experiments were performed with different feed rates and cutting speed values and the measurement results were used in a full factorial experimental design. The study is conducted by comparing the results thus obtained. The aim is to determine what roughness and cylindricity can be achieved in the case of dry, environmentally friendly machining in addition to the examined technological parameters. This study can be useful in the field of turning experimental examination on AISI 1040 grade steel workpiece cut with a coated carbide tool and cooled-lubricated with a $4 \%$ emulsion.

\section{Experimental conditions}

The conditions of the experiments performed for the study and the equipment used are listed in Table 1 . The set cutting data and fluid consumption are summarized in Table 2.

Table 1. Experimental conditions

\begin{tabular}{ll}
\hline Machine tool: & E400 universal lathe \\
Cutting tool: & Korloy DCMT 11T304-MP, grade: NC3225, $\alpha_{\mathrm{o}}=7^{\circ}, \mathrm{r}_{\varepsilon}=0.4 \mathrm{~mm}$ \\
Toolholder: & Korloy SDACR1616-H11 \\
Fixture: & Three-jaw self-centering chuck \\
Workpiece: & AISI 1040 unalloyed carbon steel, tensile strength: $770 \mathrm{MPa}$, yield strength: 430 \\
& $\begin{array}{l}\mathrm{MPa} \text {, elongation: } 25 \% \text {, cut dimensions: } \emptyset 27 \times 24 \mathrm{~mm} \\
\text { Coolant- }\end{array}$ \\
$\begin{array}{l}4 \% \text { emulsion of Rhenus FU71 T, flow rate: } \mathrm{V}_{\mathrm{p}}=150 \mathrm{ml} / \mathrm{min} \text {, oil viscosity: } 160 \\
\text { lubricant fluid: }\end{array}$ & $\mathrm{mm}^{2} / \mathrm{s}$
\end{tabular}


Table 2. Technological parameters and volumes of CL fluid

\begin{tabular}{|c|c|c|c|c|c|}
\hline No. & $\mathrm{f}[\mathrm{mm} / \mathrm{rev}]$ & $\mathrm{n}[1 / \mathrm{min}]$ & $\mathrm{v}_{\mathrm{c}}[\mathrm{m} / \mathrm{min}]$ & $\mathrm{V}_{\mathrm{p}}[\mathrm{ml} / \mathrm{min}]$ & $a_{p}[\mathrm{~mm}]$ \\
\hline 1 & 0.1 & 750 & 6060 & \multirow{4}{*}{ 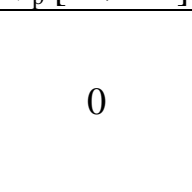 } & \multirow{8}{*}{0.5} \\
\hline 2 & 0.3 & 150 & 03.02 & & \\
\hline 3 & 0.1 & 1060 & 8001 & & \\
\hline 4 & 0.3 & 1000 & 89.91 & & \\
\hline 5 & 0.1 & 750 & 6260 & \multirow{4}{*}{150} & \\
\hline 6 & 0.3 & 150 & 03.02 & & \\
\hline 7 & 0.1 & \multirow{2}{*}{1060} & \multirow{2}{*}{89.91} & & \\
\hline 8 & 0.3 & & & & \\
\hline
\end{tabular}

After executing the experiments, the roughness measurement was performed on an AltiSurf 520 three-dimensional roughness measuring device with a CL2 confocal chromatic sensor having a vertical resolution of $0.012 \mu \mathrm{m}$. On that device, $2 \mathrm{D}$ profile and 3D areal roughness measurements were executed for this study. The profile roughness is well-known, instantly comparable to other previous or newer measurements, based on records in many literatures. However, 3D surface roughness measurements have so far been analyzed by fewer authors. Its novelty lies in the fact that the more extensive surface that is examined gives more specific, more authentic information about the given surface. The 2D and 3D measurement locations on the surfaces are shown in Figure 1a, where the specimens were rotated by $120^{\circ}$ (A-C) in the same positions (1-3), and then the results were averaged. The measured profiles were $4 \mathrm{~mm}$ long and were recorded in the same way regardless of the variable feeds, deviating from the standard, as this way the results can be authentically compared. The $3 \mathrm{D}$ areas covered $4 \times 4 \mathrm{~mm}^{2}$ on the workpieces. In each case, a Gaussian filter with a wavelength of $\lambda_{c}=0.8 \mathrm{~mm}$ was used for the evaluation after subtracting the nominal shape.

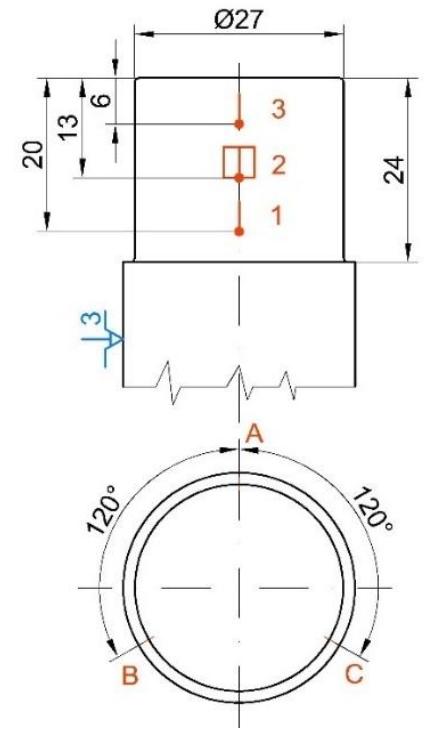

$a$,

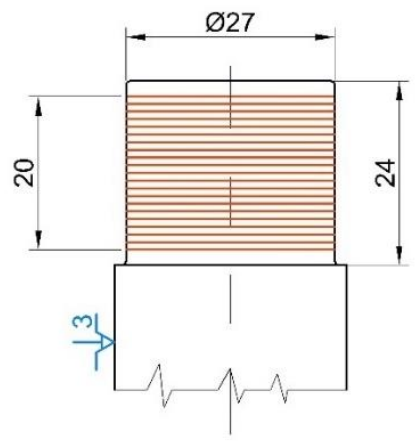

$b$,

Figure 1. Measurement plan: surface roughness (a), cylindricity $(b)$ 
Cylindricity was measured on a Taylor Hobson TalyRond 365 roundness-cylindricity measuring device with a $1 \mathrm{~mm}$ diameter ruby stylus. On the cylindrical surface 21 sections form the measured profile at a height of $20 \mathrm{~mm}$. A measurement drawing of this is shown in Figure 1b. Here, Gaussian filtering was used too.

\section{Results and Discussion}

The surface roughness is evaluated based on the parameters defined in ISO 4287:2002 and ISO 25178:2012, those of which show some unique characteristics during the evaluation. These are the material ratio $\left(R_{\mathrm{mr}}\right.$ and $\left.S_{\mathrm{mr}}\right)$, the reduced valley depth $\left(\mathrm{R}_{\mathrm{vk}}\right.$ and $\left.S_{\mathrm{vk}}\right)$, and the skewness $\left(\mathrm{R}_{\mathrm{sk}}\right.$ and $\left.\mathrm{S}_{\mathrm{sk}}\right)$ and Kurtosis $\left(\mathrm{R}_{\mathrm{ku}}\right.$ and $\left.\mathrm{S}_{\mathrm{ku}}\right)$ indices.

The first two represent complex tribological features (friction, wear, lubrication etc.), the valley depth can be used to determine the ability of the surface to retain lubricant (Sedlaček et al., 2012). Beside them, the commonly prescribed (Todhunter et al., 2017) average roughness parameters are also analyzed: $R_{a}$ and $\mathrm{S}_{\mathrm{a}}$. To determine the material ratio values, $\mathrm{c}=3 \mu \mathrm{m}$ height was set from the highest peak of the profile or topography. The definitions of these parameters are descried in Table 3 (MSZ EN ISO 4287:2002; ISO 25178-2:2012). The results are summarized in Table 4.

In the case of cylindricity, the evaluation is performed based on three indices specified in ISO 12180-1:2011: the highest peak height $C Y L_{p}$, the lowest valley depth $C Y L_{v}$ and the total height $C Y L_{t}$. All the results are shown in Table 4.

Table 3. Definitions of roughness parameters (MSZ EN ISO 4287:2002; ISO 25178-2:2012)

\begin{tabular}{|c|c|c|}
\hline Parameter & Profile (2D) & Areal (3D) \\
\hline Average (a) & $R_{a}=\frac{1}{l} \int_{l}|z(x)| d x$ & $S_{a}=\frac{1}{A} \iint_{A}|z(x, y)| d x d y$ \\
\hline Skewness (sk) & $R_{s k}=\frac{1}{R_{q}^{3}}\left[\frac{1}{l} \int_{l} z^{3}(x) d x\right]$ & $S_{s k}=\frac{1}{S_{q}^{3}}\left[\frac{1}{A} \iint_{A} z^{3}(x, y) d x d y\right]$ \\
\hline Kurtosis (ku) & $R_{k u}=\frac{1}{R_{q}^{4}}\left[\frac{1}{l} \int_{l} z^{4}(x) d x\right]$ & $S_{s k}=\frac{1}{S_{q}^{4}}\left[\frac{1}{A} \iint_{A} z^{4}(x, y) d x d y\right]$ \\
\hline Material ratio (mr) & \multicolumn{2}{|c|}{ Ratio of the area of the material at a specified height $c$ to the evaluation area } \\
\hline Red. Valley depth (vk) & \multicolumn{2}{|c|}{ Average height of the protruding dales below the core surface } \\
\hline
\end{tabular}

Table 4. Values of roughness and cylindricity parameters

\begin{tabular}{|c|c|c|c|c|c|c|c|c|c|}
\hline No. & $\begin{array}{c}\mathrm{R}_{\mathrm{a}} \\
{[\mu \mathrm{m}]}\end{array}$ & $\begin{array}{l}\mathrm{R}_{\mathrm{mr}} \\
{[\%]}\end{array}$ & $\begin{array}{c}\mathrm{R}_{\mathrm{vk}} \\
{[\mu \mathrm{m}]}\end{array}$ & $\begin{array}{c}\mathrm{S}_{\mathrm{a}} \\
{[\mu \mathrm{m}]}\end{array}$ & $\begin{array}{l}\mathrm{S}_{\mathrm{mr}} \\
{[\%]}\end{array}$ & $\begin{array}{c}S_{\mathrm{vk}} \\
{[\mu \mathrm{m}]}\end{array}$ & $\begin{array}{l}C Y L_{p} \\
{[\mu \mathrm{m}]}\end{array}$ & $\begin{array}{l}C Y L_{v} \\
{[\mu \mathrm{m}]}\end{array}$ & $\begin{array}{l}\mathrm{CYL}_{\mathrm{t}} \\
{[\mu \mathrm{m}]}\end{array}$ \\
\hline 1 & 1.10 & 21.81 & 0.65 & 1.11 & 1.32 & 0.74 & 16.36 & 14.50 & 30.86 \\
\hline 2 & 6.75 & 2.61 & 0.20 & 6.67 & 0.15 & 0.62 & 33.18 & 16.44 & 49.62 \\
\hline 3 & 1.13 & 17.73 & 0.69 & 1.13 & 7.97 & 0.66 & 21.46 & 14.44 & 35.90 \\
\hline 4 & 6.63 & 2.23 & 0.28 & 6.41 & 0.20 & 0.65 & 18.33 & 16.93 & 35.27 \\
\hline 5 & 1.32 & 17.61 & 0.81 & 1.33 & 1.18 & 0.77 & 21.61 & 14.34 & 35.95 \\
\hline 6 & 6.57 & 2.12 & 0.17 & 6.16 & 0.19 & 0.36 & 21.50 & 18.60 & 40.10 \\
\hline 7 & 1.46 & 18.16 & 0.76 & 1.45 & 3.93 & 0.84 & 17.41 & 13.63 & 31.04 \\
\hline 8 & 6.51 & 2.23 & 0.37 & 6.26 & 0.14 & 0.69 & 20.83 & 15.72 & 36.55 \\
\hline
\end{tabular}


A full factorial experimental design was used to evaluate the results and to estimate them for various cutting settings. Empirical formulas (1-9) were determined using the MathCAD software, the calculation results of which are illustrated in axonometric diagrams (Figures 2, 3, 5, and 7).

$R_{a}=-1.9795+30.029 \cdot f+0.00379 \cdot v_{c}+7.63 \cdot 10^{-4} \cdot V_{p}-0.027 \cdot f \cdot v_{c}-0.01 \cdot f \cdot V_{p}+$ $3.12 \cdot 10^{-5} \cdot v_{c} \cdot V_{p}-5.02 \cdot 10^{-5} \cdot f \cdot v_{c} \cdot V_{p}$

$S_{a}=-2.07+31.214 \cdot f+0.00604 \cdot v_{c}+0.00446 \cdot V_{p}-0.052 \cdot f \cdot v_{c}-0.045 \cdot f \cdot V_{p}-7.951 \cdot$

$10^{-6} \cdot v_{c} \cdot V_{p}+3.193 \cdot 10^{-4} \cdot f \cdot v_{c} \cdot V_{p}$

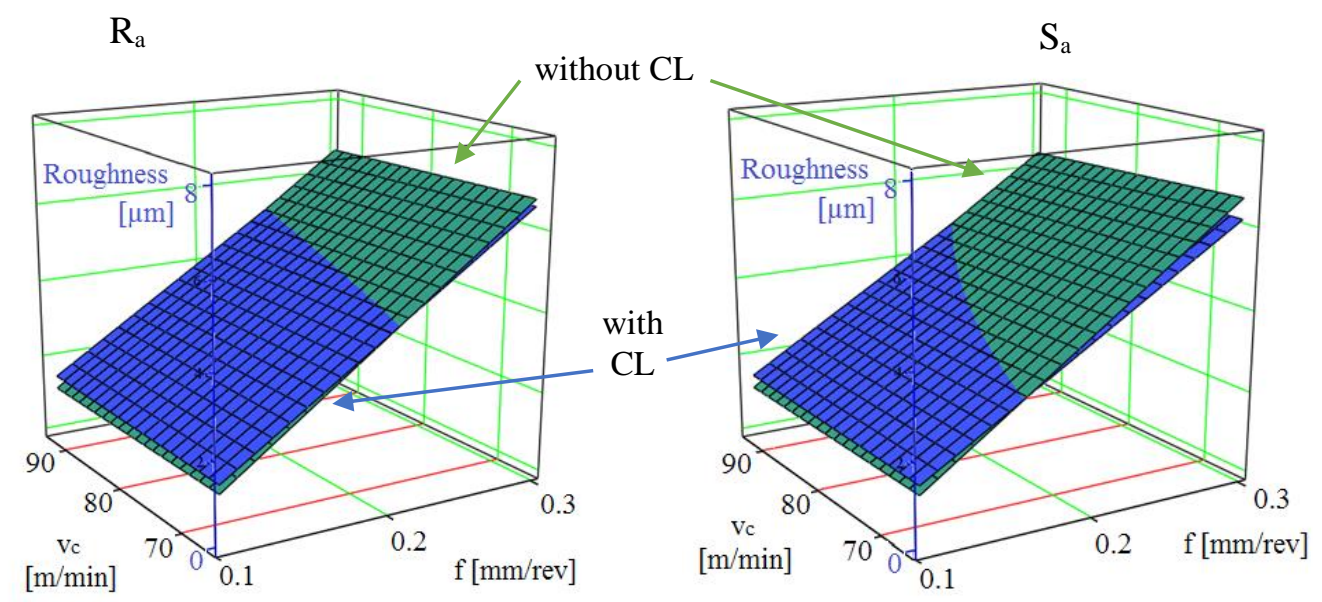

Figure 2. Changes in the values of $R_{a}$ and $S_{a}$

$R_{m r}=45.7594-140.805 \cdot f-0.218 \cdot v_{c}-0.149 \cdot V_{p}+0.68 \cdot f \cdot v_{c}+0.458 \cdot f \cdot V_{p}+0.00164 \cdot$

$v_{c} \cdot V_{p}-0.00507 \cdot f \cdot v_{c} \cdot V_{p}$

$S_{m r}=-22.1763+74.031 \cdot f+0.365 \cdot v_{c}+0.092 \cdot V_{p}-1.211 \cdot f \cdot v_{c}-0.301 \cdot f \cdot V_{p}-0.00142 \cdot$

$v_{c} \cdot V_{p}+0.00466 \cdot f \cdot v_{c} \cdot V_{p}$

Using the values in Table 3, the Equations (1-6) and Figures 2, 3, 5 may help analyze the effect of cooling and lubrication on the surface roughness. The values of the average roughness parameters are almost identical in pairs (Figure 2). Here it can be found that by reducing the feed, better surface roughness was obtained with dry machining, at higher feed rates the values increase towards the values of wet cutting. The cutting speed shows the exact opposite, where the increase of it leads to a decrease in $R_{a}$ and $S_{a}$ values on both cooling conditions. Although the average roughness of the dry turned surface have higher average values with the increase of productivity ( $f, n$ or $v_{c}$ ), the difference in terms of environmental load and cost reduction is negligible.

The material ratio values (Figure 3) are favorable for low feed rate, between 17.5-22\% for $\mathrm{R}_{\mathrm{mr}}$ and $1.1-8 \%$ for $\mathrm{S}_{\mathrm{mr}}$ can be expected. On the other hand, an opposite characteristic is found among the 2D and 3D measurement results, based on the cutting speed, so this parameter shows significant differences, an exceptional case. The reduction of the speed for the case of profile examination, and the increase for the case of areal measurement results a higher material ratio. Further investigations are needed to explain this contradiction. 


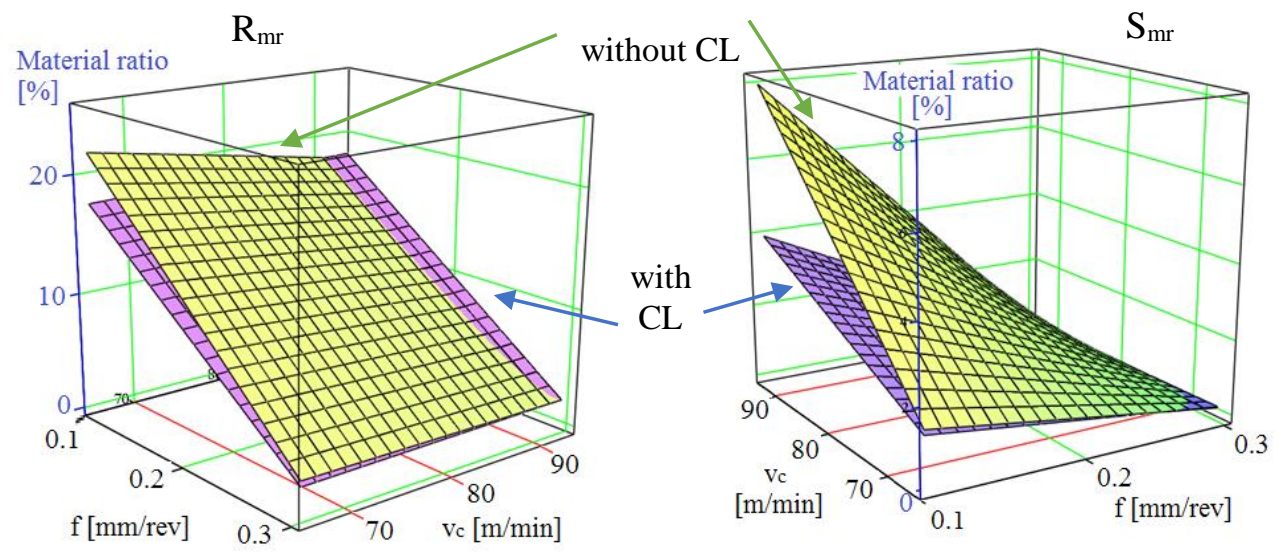

Figure 3. Changes in the values of $R_{m r}$ and $S_{m r}$

For 2D measurement, the material ratio values (Figure 3) increase with decreasing feed and cutting speed in both cases, where the increase in dry machining is greater. Accordingly, the largest difference is at the minimum feed rate and speed set which is $\Delta \mathrm{R}_{\mathrm{mr}}=4.2 \%$. In the examined range, the material ratio of dry machined workpieces in most cases exceeds the wet machining values, which means that at lower feed rates and cutting speeds, dry turned surfaces can be expected to have better wear resistance and dimensional stability. The values of the 3D parameter show a different character from the previous ones, where an increase in the material ratio can be achieved in the same way by reducing the feed rate, but also with the increase of the cutting speed. This difference and the significant deviations between the results measured on the individual test pieces between the $R_{m r}$ and $S_{m r}$ value pairs are yet unknown, thus further investigations are needed to find out the cause.

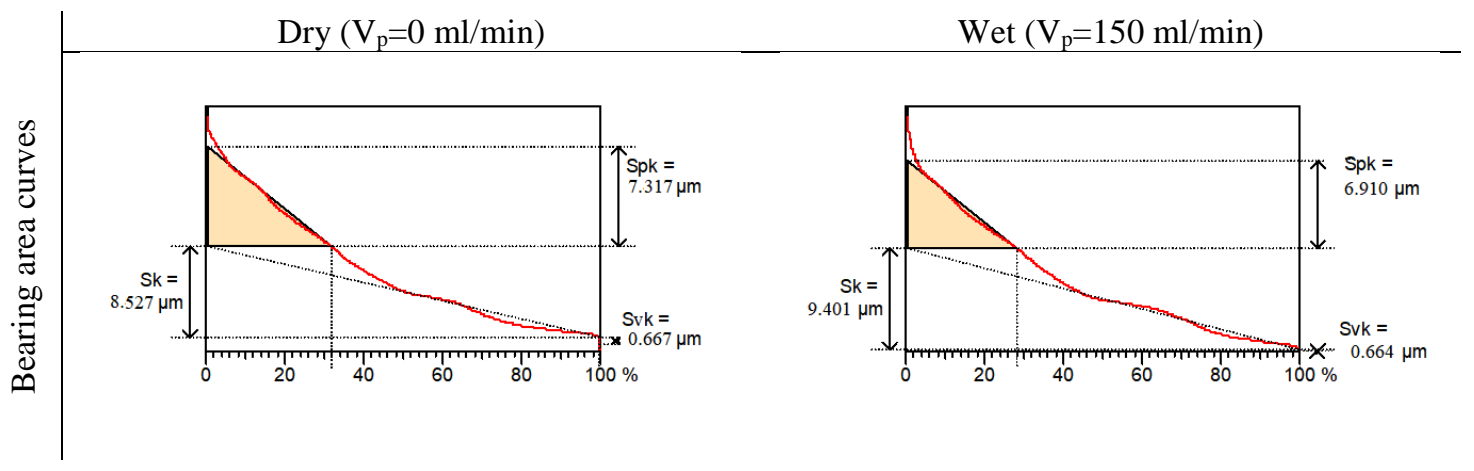

Figure 4. 3D functional parameters on Abbott-Firestone curves

Figure 4 shows the Abbott-Firestone curves where the average values of the functional areal parameters $\left(S_{\mathrm{pk}}, S_{\mathrm{k}}, S_{\mathrm{vk}}\right)$ between dry and wet machining can be observed. The curves are different from the ideal, so further studies may be needed. This also supports the general theory that during dry machining, the quickly wear surface layer height $\left(S_{\mathrm{pk}}\right)$ become larger and the core height $\left(\mathrm{S}_{\mathrm{k}}\right)$ is smaller which is characteristic to the lifetime of the part. The differences are slightly significant: $\Delta \mathrm{S}_{\mathrm{pk}}=0.407 \mu \mathrm{m}$ and $\Delta \mathrm{S}_{\mathrm{k}}=-0.874 \mu \mathrm{m}$, respectively. Both are disadvantageous in point of view of functionality and lifetime. Also, the $S_{\mathrm{vk}}$ parameter remained on low value regardless of the cooling, which means that turned surfaces do not have good ability for retaining lubricant. 
$R_{v k}=0.7906-2.559 \cdot f+0.00117 \cdot v_{c}+0.00506 \cdot V_{p}+0.00514 \cdot f \cdot v_{c}-0.025 \cdot f \cdot V_{p}-$ $5.052 \cdot 10^{-5} \cdot v_{c} \cdot V_{p}+2.752 \cdot 10^{-4} \cdot f \cdot v_{c} \cdot V_{p}$

$S_{v k}=1.1387-1.973 \cdot f-0.00505 \cdot v_{c}-3.947 \cdot 10^{-4} \cdot V_{p}+0.02 \cdot f \cdot v_{c}-0.02 \cdot f \cdot V_{p}+2.226 \cdot$

$10^{-5} \cdot v_{c} \cdot V_{p}+1.639 \cdot 10^{-4} \cdot f \cdot v_{c} \cdot V_{p}$

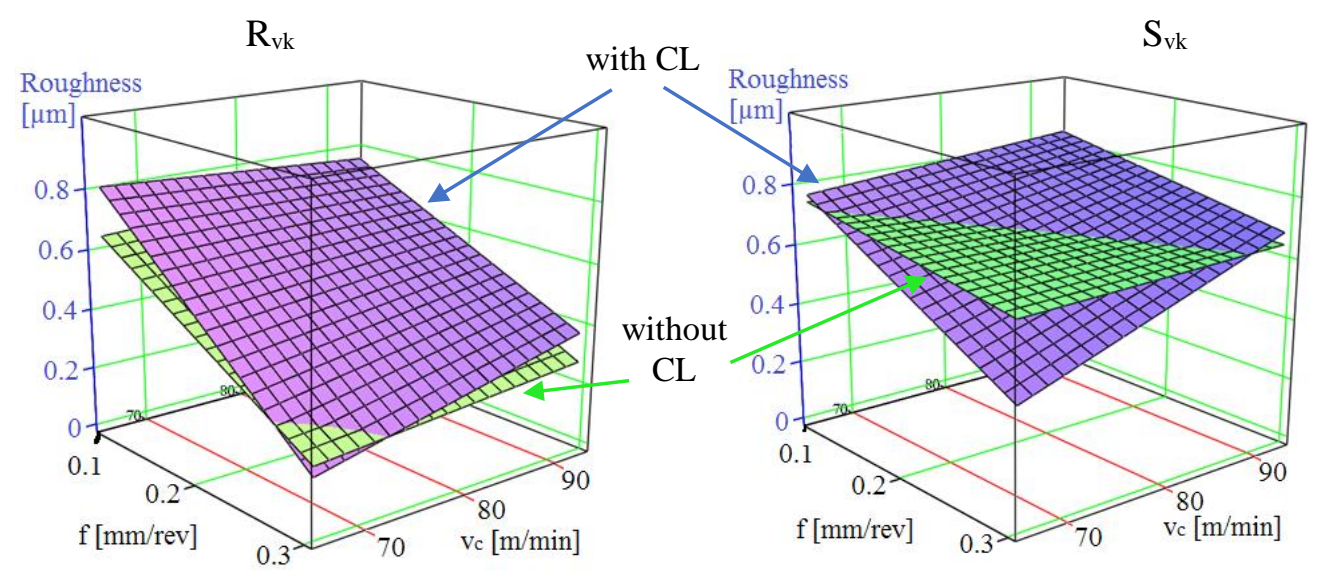

Figure 5. Changes in the values of $R_{v k}$ and $S_{v k}$

The values of the reduced valley depth parameter (Figure 5) show maximum differences of $\Delta \mathrm{R}_{\mathrm{vk}}{ }^{\max }=0.64 \mu \mathrm{m}$ and $\Delta \mathrm{S}_{\mathrm{vk}}{ }^{\max }=0.48 \mu \mathrm{m}$. An increase can be observed with decreasing feed and increasing cutting speed, however, in the case of dry machined surfaces this change is smaller (the extent of difference for dry machining is $72 \%$ for $\mathrm{R}_{\mathrm{vk}}$ and $51 \%$ for $\mathrm{S}_{\mathrm{vk}}$, compared to wet cases) in the examined range. A higher measured value indicates better lubricant retention, so in this respect in dry machining we recommend the use of lower feed and cutting speed values, though the $2 \mathrm{D}$ and $3 \mathrm{D}$ values remain lower at these settings, but the differences are very little: $\Delta R_{v k}=0.16 \mu \mathrm{m}$ and $\Delta S_{v k}=0.03 \mu \mathrm{m}$.

For all examined parameters, the effect of feed is dominant, followed by the cutting speed and then the cooling-lubrication. The combined effect of the setting data depends on the characteristics of the former ones, so that the feed and the cutting speed together are relatively decisive, the others are smaller and mostly negligible. So, it means that cooling-lubrication, at the amount used in the present study, has little effect on the reduced valley parameters. Although the omission of the fluid leads to a deterioration of roughness, its magnitude is not significant, in the examined range.

The skewness and kurtosis of the profile curves and topographies were also evaluated during the roughness measurement. The values obtained are summarized in Table 5, organized according to the measured specimen and the measurement location (Figure 1a). The values of these parameters are distributed between 0.33-0.83 and 2.36-2.95, for skewness and kurtosis, respectively. Increasing the feed also increases the skewness and reduces the kurtosis, the cutting speed basically does not / only slightly change both. The effect of cooling and lubrication is not noticeable.

A positive value of skewness means from a tribological point of view (Whitehouse, 2002) that there is a relatively larger part of the material below the center line, i.e., at the bottom of the profile, and there are narrow peaks between them. From the aspect of wear, the latter are the initially load-bearing and wear layer, so the turned surface cannot be characterized by good wear resistance and dimensional 
stability. This is consistent with the reduced peak height $\left(\mathrm{R}_{\mathrm{pk}}, \mathrm{S}_{\mathrm{pk}}\right)$ parameters' values and their associated findings.

Table 5. Skewness-kurtosis values of profile and areal roughness

\begin{tabular}{|c|c|c|c|c|c|c|c|c|c|c|c|}
\hline \multirow[b]{2}{*}{ No. } & \multirow[b]{2}{*}{ Place } & \multicolumn{2}{|c|}{$2 \mathrm{D}$} & \multicolumn{2}{|c|}{$3 \mathrm{D}$} & \multirow[b]{2}{*}{ No. } & \multirow[b]{2}{*}{ Place } & \multicolumn{2}{|c|}{$2 \mathrm{D}$} & \multicolumn{2}{|c|}{$3 \mathrm{D}$} \\
\hline & & $\mathrm{R}_{\mathrm{sk}}[-]$ & $\mathrm{R}_{\mathrm{ku}}[-]$ & $\mathrm{S}_{\mathrm{sk}}[-]$ & $S_{\mathrm{ku}}[-]$ & & & $\mathrm{R}_{\mathrm{sk}}[-]$ & $\mathrm{R}_{\mathrm{ku}}[-]$ & $S_{\mathrm{sk}}[-]$ & $\mathrm{S}_{\mathrm{ku}}[-]$ \\
\hline \multirow{3}{*}{1} & $\mathrm{~A}$ & \begin{tabular}{|l|}
0.48 \\
\end{tabular} & 2.56 & 0.46 & 2.71 & \multirow{3}{*}{5} & $\mathrm{~A}$ & \begin{tabular}{|l|}
0.35 \\
\end{tabular} & 2.52 & 0.33 & 2.59 \\
\hline & B & 0.39 & 2.57 & 0.35 & 2.81 & & B & 0.43 & 2.44 & 0.50 & 2.53 \\
\hline & $\mathrm{C}$ & 0.56 & 2.84 & 0.47 & 2.77 & & $\mathrm{C}$ & 0.47 & 2.59 & 0.54 & 2.76 \\
\hline \multirow{3}{*}{2} & A & & 2.36 & 0.77 & 2.48 & \multirow{3}{*}{6} & A & 0.78 & 2.55 & 0.83 & 2.73 \\
\hline & B & & 2.36 & 0.76 & 2.44 & & B & 0.75 & 2.45 & 0.77 & 2.58 \\
\hline & C & 0.77 & 2.50 & 0.78 & 2.48 & & $\mathrm{C}$ & 0.77 & 2.53 & 0.81 & 2.63 \\
\hline \multirow{3}{*}{3} & A & & & & 2.71 & \multirow{3}{*}{7} & A & 0.40 & 2.44 & 0. & 2.50 \\
\hline & B & & 2.74 & 0.50 & 2.70 & & B & 0.48 & 2.46 & 0.50 & 2.55 \\
\hline & $\mathrm{C}$ & 0.55 & 2.73 & 0.50 & 2.70 & & $\mathrm{C}$ & 0.34 & 2.37 & 0.33 & 2.45 \\
\hline \multirow{3}{*}{4} & $\mathrm{~A}$ & 0.76 & 2.52 & 0.75 & 2.51 & & $\mathrm{~A}$ & 0.74 & 2.49 & 0.77 & 2.56 \\
\hline & B & 0.76 & 2.50 & 0.83 & 2.70 & & B & 0.78 & 2.56 & 0.76 & 2.60 \\
\hline & $\mathrm{C}$ & 0.75 & 2.47 & 0.81 & 2.62 & & $\mathrm{C}$ & 0.78 & 2.58 & 0.80 & 2.69 \\
\hline
\end{tabular}

Kurtosis is scattered between the values indicated above, which are values below 3, but not far from it. That is, the profiles and topographies are slightly rounder than the normally distributed Gaussian surfaces. Turning, on the other hand, is characterized by rounded valleys (cut by the edge radius) with pointed peaks. The values also reflect this, so these experimental surfaces are not wear-resistant and are only slightly able to keep the lubrication condition. The same were found based on the values of the functional parameters measured from the Abbott-Firestone curves (Figure 4).

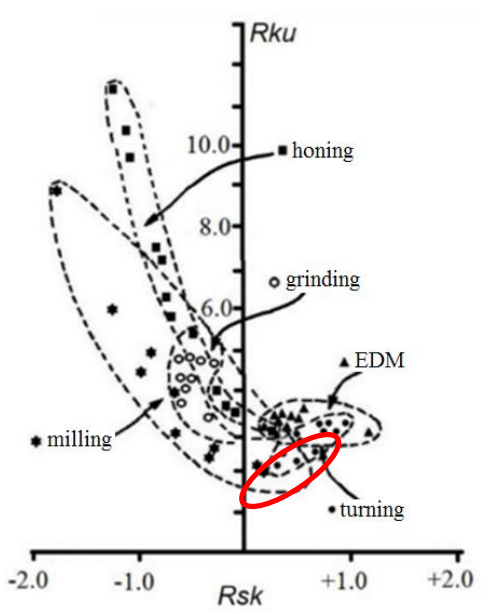

$a$,

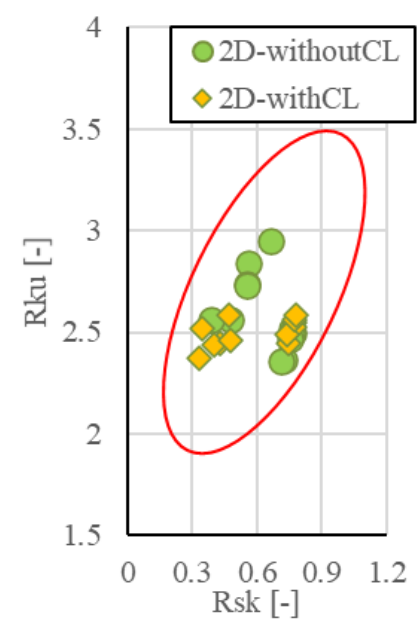

$b$,

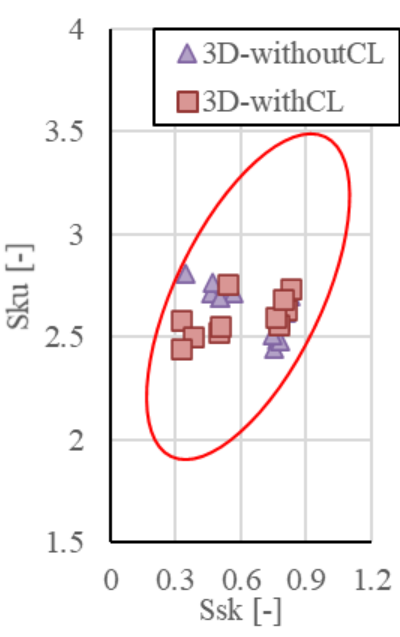

$c$,

Figure 6. Tribological topographic map based on literature (Whitehouse, 1994)

(a) and on experimental results $(b, c)$

The skewness-kurtosis value pairs in Table 5 are plotted separately for 2D (Figure $6 \mathrm{~b}$ ) and 3D (Figure 6c) parameters and the results are evaluated and compared with data from a tribological topographic 
map (Figure 6a) taken from the literature (Whitehouse, 1994). All diagrams show the range of value pairs characteristic to the turned surface, marked with a red ellipse. It can be clearly seen that each value pair is in the marked range, in this respect the surfaces of the test pieces are regular, showing the expected results. This also means that the 2D and 3D parameter pairs have very similar characteristics. The set of points is concentrated within two smaller areas within the turning zone, which are independent of the method of measurement and the application of cooling-lubrication.

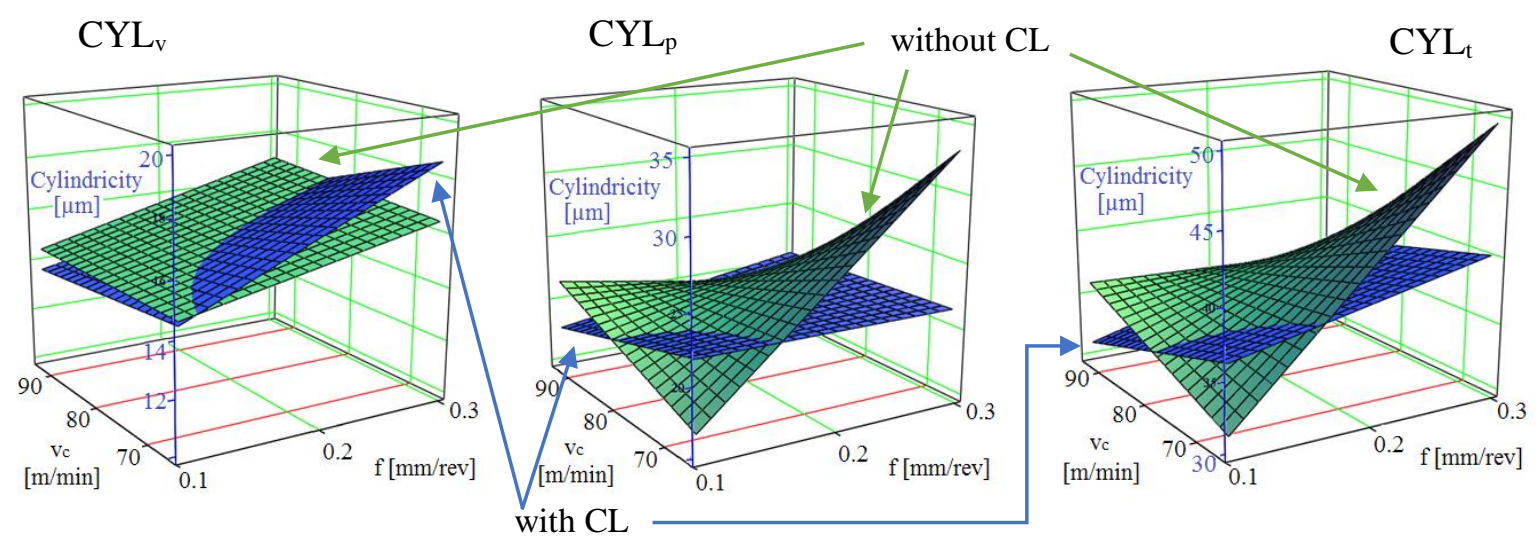

Figure 7. Changes in the values of cylindricity parameters $\left(C Y L_{v}, C Y L_{p}, C Y L_{t}\right)$

$$
\begin{aligned}
& C Y L_{v}=14.3406+3.046 \cdot f-0.012 \cdot v_{c}-0.02 \cdot V_{p}+0.101 \cdot f \cdot v_{c}+0.297 \cdot f \cdot V_{p}+1.737 \cdot \\
& 10^{-4} \cdot v_{c} \cdot V_{p}-0.00333 \cdot f \cdot v_{c} \cdot V_{p} \\
& C Y L_{p}=-28.5287+325.477 \cdot f+0.553 \cdot v_{c}+0.424 \cdot V_{p}-3.661 \cdot f \cdot v_{c}-2.434 \cdot f \cdot V_{p}- \\
& 0.00504 \cdot v_{c} \cdot V_{p}+0.028 \cdot f \cdot v_{c} \cdot V_{p} \\
& C Y L_{t}=-14.176+328.401 \cdot f+0.541 \cdot v_{c}+0.411 \cdot V_{p}-3.558 \cdot f \cdot v_{c}-2.161 \cdot f \cdot V_{p}- \\
& 0.00497 \cdot v_{c} \cdot V_{p}+0.025 \cdot f \cdot v_{c} \cdot V_{p}
\end{aligned}
$$

Based on the values in Table 3, Equations (7-9) and the diagrams (Figure 7) are used to examine the cylindricity parameters. For all three indices, it can be found that the shape error is smaller at the maximum cutting speed and minimum feed rate with wet machining, in the test range. The CYL values increase with the increase of feed and the decrease of cutting speed. The degree of change is small in dry machining (max. 17\%) and much more significant in wet machining (max. 36\%). For this reason, the rate of profile valley error $\left(\mathrm{CYL}_{\mathrm{v}}\right)$ is smaller in the environmentally friendly case when working with a lower cutting speed.

Basically, the $\mathrm{CYL}_{v}$ values do not show large differences between dry and wet conditions, the maximum deviation is $\Delta \mathrm{CYL}_{\mathrm{v}}=2.16 \mu \mathrm{m}$ (at max. feed and min. speed), so the characteristics of the maximum peak height $\mathrm{CYL}_{\mathrm{p}}$ mainly determine the total height difference $\mathrm{CYL}_{\mathrm{t}}$. Thus, for these parameters, it can be said that increasing the feed increases them in most cases, except at the maximum speed it does not change them substantially. Increasing the cutting speed decreases them in the case of wet machining and increases them on dry turned surfaces, except for a greater decrease at the maximum feed compared to the wet case. Considering these, a smaller cylindricity error is expected at lower feed rates and lower speeds when turning steel, here the largest deviation is $\Delta \mathrm{CYL}_{\mathrm{t}}=5.1 \mu \mathrm{m}$, in the examined range. 


\section{Summary}

In this paper, as the environmentally friendly machining is very important nowadays, non-alloy steel workpieces were turned on which the consequences of the abandonment of cooling and lubrication were investigated on surface roughness and cylindricity by setting different feed and cutting speeds. The experimental results were processed by a full factorial experimental design, based on which the evaluation was performed. The following statements were made:

- Feed rate had the greatest effect on average roughness, followed by the cutting speed and after them the volume of coolants and lubricants, which was negligible (max. deviation: $0.51 \mu \mathrm{m}$ ). In most cases the higher cutting speed resulted lower roughness on dry turned pieces. Thus, we recommend the use of higher cutting speeds and relatively lower feed rates.

- In terms of wear resistance and dimensional stability, the material ratio parameters showed a favorable case for dry machining with a lower feed value.

- The values of the reduced valley depth parameters were basically low, their increase can be achieved with decreasing values of the feed and cutting speed, where the lubricant retention ability is better. In overall, in dry machining, at the investigated conditions the best values $\left(R_{v k}=0.65\right.$ $\left.\mu \mathrm{m}, \mathrm{S}_{\mathrm{vk}}=0.74 \mu \mathrm{m}\right)$ can be achieved with low feed rate $\left(\mathrm{f}_{\mathrm{z} 1}=0.1 \mathrm{~mm} / \mathrm{rev}\right)$ and cutting speed $\left(\mathrm{v}_{\mathrm{c} 1}=70\right.$ $\mathrm{m} / \mathrm{min})$.

- Roughness skewness-kurtosis value pairs are in the range indicated in the tribological topographic map based on the literature (Whitehouse, 1994). Kurtosis values are scattered in a narrower range and the skewness values in a wider range. Kurtosis is scattered between the values indicated above, which are values below 3 , but not far from it. That is, the profiles and topographies are slightly rounder than the normally distributed Gaussian surfaces.

Based on the analysis in this paper it is possible to analyze in the future on other materials, having different toughness and strengths, used in industry and with applying different coolants-lubricants.

\section{Acknowledgement}

Project no. NKFI-125117 has been implemented with the support provided from the National Research, Development and Innovation Fund of Hungary, financed under the K_17 funding scheme.

\section{References}

[1] Dudás, I., Friedhelm, L., Varga, Gy. (2010). Környezetbarát technológiák a gépgyártásban: forgácsolás szárazon, minimális hütéssel-kenéssel. Budapest, Müszaki Könyvkiadó, 308 p.

[2] Kundrák, J., Varga, G., Deszpoth, I. (2018). Analysis ofe of environment load in alternative manufacturing procedures. WSEAS Transactions on Environment and Development, 14, 313-320.

[3] Saliminia, A., Abootorabi, M. M. (2019). Experimental investigation of surface roughness and cutting ratio in a spraying cryogenic turning process. Machining Science and Technology, 23(5), 779-793. https://doi.org/10.1080/10910344.2019.1584821

[4] Bonfá, M. M., Costa, É. S., Sales, W. F., Amorim, F. L., Maia, L. H. A., Machado, Á. R. (2019). Evaluation of tool life and workpiece surface roughness in turning of AISI D6 hardened steel using PCBN tools and minimum quantity of lubricant (MQL) applied at different directions. The International Journal of Advanced Manufacturing Technology, 103, 971-984. https://doi.org/10.1007/s00170-019-03619-z 
[5] Derani, M. N., Ratnam, M. M. (2021). The use of tool flank wear and average roughness in assessing effectiveness of vegetable oils as cutting fluids during turning - a critical review. The International Journal of Advanced Manufacturing Technology, 112, 1841-1871.

https://doi.org/10.1007/s00170-020-06490-5

[6] Gariani, S., Elsayed, M., Shyha, I. (2021). Optimisation of cutting fluid concentration and operating parameters based on RSM for turning Ti-6Al-4V. The International Journal of Advanced Manufacturing Technology, (preprint). https://doi.org/10.21203/rs.3.rs-363081/v1

[7] Gupta, M. K., Mia, M., Jamil, M., Singh, R., Singla, A. K., Song, Q., Liu, Z., Khan, A. M., Rahman, M. A., Sarikaya, M. (2020). Machinability investigations of hardened steel with biodegradable oilbased MQL spray system. The International Journal of Advanced Manufacturing Technology, 108, 735-748. https://doi.org/10.1007/s00170-020-05477-6

[8] Niknam, S. A., Jalali, A. (2020). Effects of lubricants and flow rates on the surface roughness and chip thickness when MQL turning of aero-engine aluminum alloys 6061-T6 and 7076-T6. The International Journal of Advanced Manufacturing Technology, 110, 2015-2022. https://doi.org/10.1007/s00170-020-05979-3

[9] Zaman, P. B., Dhar, N. R. (2019). Design and evaluation of an embedded double jet nozzle for MQL delivery intending machinability improvement in turning operation. Journal of Manufacturing Processes, 44, 179-196. https://doi.org/10.1016/j.jmapro.2019.05.047

[10] Gupta, M. K., Jamil, M., Wang, X., Song, Q., Liu, Z., Mia, M., Hegab, H., Khan, A. M., Collado, A. G., Pruncu, C. J., Imran, G. M. (2019). Performance evaluation of vegetable oil-based nano-cutting fluids in environmentally friendly machining of Inconel-800 alloy. Materials, 12(17), ArtNo.2792. https://doi.org/10.3390/ma12172792

[11] Leppert, T. (2011). Effect of cooling and lubrication conditions on surface topography and turning process of C45 steel. International Journal of Machine Tools and Manufacture, 51(2), 120-126. https://doi.org/10.1016/j.ijmachtools.2010.11.001

[12] Joshi, K. K.; Kumar, R., Anurag (2018). An experimental investigations in turning of Incoloy 800 in dry, MQL and flood cooling conditions. Procedia Manufacturing, 20, 350-357. https://doi.org/10.1016/j.promfg.2018.02.051

[13] Varga, G., Kundrák, J. (2013). Effect of environmentally conscious machining on machined surface quality. Applied Mechanics and Materials, 309, 35-42. https://doi.org/10.4028/www.scientific.net/AMM.309.35

[14] Das, A., Patel, S. K., Arakha, M., Dey, A., Biswal, B. B. (2021). Processing of hardened steel by MQL technique using nano cutting fluids. Materials and Manufacturing Processes, 36(3), 316-328. https://doi.org/10.1080/10426914.2020.1832688

[15] Sivaiah, P., Chakradhar, D. (2020). Identifying the effectiveness of manner of cryogenic coolant supply in different cryogenic cooling techniques in turning process-a review. Machining Science and Technology, 24(6), 948-999. https://doi.org/10.1080/10910344.2020.1815039

[16] Araújo, R. P., Rolim, T. L., Oliveira, C. A., Moura, A. E., Silva, J. C. A. (2019). Analysis of the surface roughness and cutting tool wear using a vapor compression assisted cooling system to cool the cutting fluid in turning operation. Journal of Manufacturing Processes, 44, 38-46. https://doi.org/10.1016/j.jmapro.2019.05.040

[17] Bogajo, I. R., Tangpronprasert, P., Virulsri, C., Keeratihattayakorn, S., Arrazola, P. J. (2020). A novel indirect cryogenic cooling system for improving surface finish and reducing cutting forces when turning ASTM F-1537 cobalt-chromium alloys. The International Journal of Advanced Manufacturing Technology, 111(7), 1971-1989. https://doi.org/10.1007/s00170-020-06193-x 
[18] Kim, D. M., Banerjee, N., Park, H. W. (2018). Predictive modeling for the cryogenic cooling condition of the hard turning process. The International Journal of Advanced Manufacturing Technology, 99(9), 2877-2891. https://doi.org/10.1007/s00170-018-2660-z

[19] Gajrani, K. K., Sankar, M. R., Dixit, U. S. (2018). Environmentally friendly machining with MoS2filled mechanically microtextured cutting tools. Journal of Mechanical Science and Technology, 32(8), 3797-3805. https://doi.org/10.1007/s12206-018-0732-5

[20] Kundrak, J., Felho, C. (2016). 3D roughness parameters of surfaces face milled by special tools. Manufacturing Technology, 16(3), 532-538. https://doi.org/10.21062/ujep/x.2016/a/12132489/MT/16/3/532

[21] Felho, C., Kundrak, J. (2012). Characterization of topography of cut surface based on theoretical roughness indexes. Key Engineering Materials, 496, 194-199. https://doi.org/10.4028/www.scientific.net/KEM.496.194

[22] Masoudi, S., Esfahani, M. J., Jafarian, F., Mirsoleimani, S. A. (2019). Comparison the effect of MQL, wet and dry turning on surface topography, cylindricity tolerance and sustainability. International Journal of Precision Engineering and Manufacturing - Green Technology, 6, 1-13. https://doi.org/10.1007/s40684-019-00042-3

[23] Sedlaček, M., Podgornik, B., Vižintin, J. (2012). Correlation between standard roughness parameters skewness and kurtosis and tribological behaviour of contact surfaces. Tribology International, 48, 102-112. https://doi.org/10.1016/j.triboint.2011.11.008

[24] Todhunter, L. D., Leach, R., Lawes, S., Blateyron, F. (2017). Industrial survey of ISO surface texture parameters. CIRP Journal of Manufacturing Science and Technology, 19, 84-92. https://doi.org/10.1016/j.cirpj.2017.06.001

[25] Geometrical product specifications (GPS). Surface texture: Profile method. Terms, definitions and surface texture parameters (MSZ EN ISO 4287:2002)

[26] Geometrical product specifications (GPS) - Surface texture: Areal - Part 2: Terms, definitions and surface texture parameters (ISO 25178-2:2012)

[27] Whitehouse, D. J. (2002). Surfaces and their Measurement. CRC Press, 395 p.

[28] Whitehouse, D. J. (1994). Handbook of surface metrology. IOP Publishing Ltd., Bristol and Philadelphia, $944 \mathrm{p}$. 